\title{
The Biological Characteristics of Raspberry and the Research of Biology Irrigation System
}

\author{
Lin $\mathrm{Na}^{1}$, Du Hang ${ }^{1}$, Xing Ying Ying ${ }^{1}$, Liu ZiHao ${ }^{1}$
}

\author{
${ }^{1}$ Binzhou Polytechnic, Binzhou, Shandong 256600, China \\ Email:ㄹz3383102@163.com
}

\begin{abstract}
The intelligent water and fertilizer integration device integrates the environmental monitoring system and the intelligent water and fertilizer integration system, which is composed of three parts. Wireless sensor network is composed of multiple sensor nodes of wireless network, wireless sensor network (WSN) is responsible for collecting information of crop growth environment (soil moisture, air temperature and humidity, light intensity), cucumber system device by all-in-one, water supply, water supply equipment, such as ratio of cucumber system is responsible for according to the instructions must be conductivity and ph value of sewage sludge, Then the soil is fertilized and irrigated. The sensor node and the water and fertilizer integrated machine jointly form a wireless sensor network, with the sensor as the terminal node and the water and fertilizer integrated machine as the coordination node. Raspberry picking garden by using intelligent integration equipment, water can save a lot of manpower material resources, saving a lot of artificial cost, the calculation of $100 \mathrm{mu}$ book raspberry picking garden using smart cucumber in equipment picked two season costs about 1 million yuan a year, if the binzhou city fruit and vegetable garden all use the equipment, save cost hundreds of millions of dollars a year.
\end{abstract}

Keywords: intelligent water, raspberry, cucumber system device

\section{INTRODUCTION}

Raspberry originated in Europe, Asia, America, belongs to the genus Rubus of Rosaceae, perennial Jiangye fruit trees, small shrubs. There are more than 20 kinds of wild resources in China. The northern common style "holding basin". The distribution area is very wide. Artificial cultivated varieties are divided into black poison, red raspberry two series varieties, China's Liaoning, Jilin, Shandong, Jiangsu and other provinces have a certain area of cultivation. At present, Binzhou, Zaozhuang, Yantai, Zibo and other places in our province have been introduced trial, all show a strong adaptability. Raspberry is called "golden fruit" in the world. Its fruit is a small berry, sweet and aromatic, rich in nutrition, containing $5.58 \%-10.67 \%$ sugar, $0.62 \%-2.17 \%$ acid, and rich in vitamin C1.B1, B2, B12, amino acids and various mineral elements[1]. Raspberry is not only a delicious raw fruit, but also an excellent raw material for processing jam, juice, fruit wine and preserves[2]. It also has the medical value of appetizing, helping digestion, lowering blood pressure and so on, and has a very broad market development prospect.

At present, China is transforming from traditional agriculture to modern intelligent agriculture. The core of modern intelligent agriculture is intelligent

agricultural equipment, which can greatly improve the production efficiency and quality safety of agricultural products. Therefore, vigorously developing the intelligence of agricultural equipment is the key factor to promote the development of modern intelligent agriculture[2]. Iot of emerging technology is applied to agricultural equipment can significantly improve the intelligence of agricultural equipment, is now able to drive the modern agricultural development and key technologies of wisdom, but at present the Internet of things technology in the application of agricultural equipment is not yet mature, there are still many problems need to be solved, such as: the high cost of agricultural equipment, stability is not high, intelligent still need further enhance and so on.At present,the country attaches great importance tothe research of intelligent agricultural equipment. Water and fertilizer integration technology is a new technology that integrates irrigation and fertilization. Water soluble fertilizer is added into irrigation water, and water and fertilizer are delivered to the root of crops with the help of drip irrigation pipe network. The technology integrates water and fertilizer, which can effectively save time and labor, improve the utilization rate of water and fertilizer, and save water and fertilizer resources. Applying the Internet of Things technology to the integrated intelligent irrigation system of water and fertilizer can improve the intelligence, reliability and economy of the system more than the traditional irrigation system[3]. It can liberate farmers' hands, further save water and fertilizer, scientifically irrigate and fertilize crops according to the rules of water and fertilizer 
demand of crops, so that crops are in the most suitable nutritional environment, and improve the yield and quality of crops.

\section{BACKGROUND}

\subsection{Probabilistic Automata}

Demand analysis of cooperative units.At present, the raspberry picking garden area of $100 \mathrm{mu}$, about 600 fruit trees per mu, two seasons a year each fruit tree per mu 2000 catties, a total of 200 thousand catties, such a planting scale has been relying on manpower to water and fertilizer, the cost of a lot of manpower and material resources, but also there is uneven irrigation and fertilizer, annual consumption of one million yuan[4]. Therefore, the cooperative is in urgent need of intelligent integrated water and fertilizer equipment suitable for the growth and cultivation of raspberry to free hands and save costs, and create more economic and social benefits.

Research status, level and development trend at home and abroad.After years of research, remarkable achievements have been made in domestic research on automatic precision fertilization equipment. You Lanting (2011) developed a self-propelled watering machine to fertilized and irrigated according to the humidity of the substrate in the greenhouse. Yafang Wang (2015) adopted the combination of irrigation and proportional fertilization device, soil moisture monitoring system and control system to realize the design of a complete set of automatic integrated water and fertilizer system[5]. Li Yinkun et al. (2017) developed an integrated automatic control equipment for greenhouse water and fertilizer by using the soil moisture content model. Hao Mengchao (2017) designed an automatic integrated system of water and fertilizer based on PLC control, which monitored soil EC value through EC sensor to control fertilizer amount. Zhao Jin (2018) et al., using STM32 as the main controller, developed a water and fertilizer integrated machine with proportional control according to $\mathrm{EC}$ or $\mathrm{pH}$ value in water and fertilizer liquid. Xi Ruobing (2019) developed a solar greenhouse integrated water and fertilizer machine based on Raspberry Pi. By collecting environmental factors in the greenhouse, and according to the knowledge base, the injected fertilizer of the fertilizer absorption pump is regulated by PWM.

The technology of integrated water and fertilizer started earlier in foreign countries. In the 1960s, Israel began to develop the technology of integrated water and fertilizer irrigation and established a national water transmission system, and applied it in the fields of irrigation and fertilizer engineering such as greenhouse crops and fruit trees (A.Sivagami et al., 2019). In the 1970s, drip fertilization technology developed rapidly in
Australia, Israel, Mexico, New Zealand, the United States and South Africa (Xu Wenqi, 2018). In the 1980s,Israel developed a self-propelled mechanical irrigation system, the system includes cans, venturi fertilizer fertilizer and fertilizer equipment such as hydraulic drive fertilizer injector, and the computer control technology into the system, improved the nutrient distribution uniformity, crop absorption efficiency of the water has also been further enhance (han-song li, etc., 2018). Now, Israel surpasses $80 \%$ of irrigated land uses drip irrigation, with water utilization rate up to $95 \%$ and nitrogen fertilizer utilization rate above $80 \%$, forming a huge industrial group, such as Netafim Drip Irrigation Technology Equipment Company (Megersa Girma et al., 2015; Yin Feihu, 2018) At present, developed countries combine computers, microcontrollers, $\mathrm{pH}$ sensors and $\mathrm{EC}$ value sensors, and use advanced control algorithms to achieve precise control of fertilizer dosage, which has formed a perfect technical system for equipment production, fertilizer preparation, promotion and service (Chen Chao et al., 2018; Zong Zheying et al., 2019).

\subsection{Present situation of this test}

Water fertilizer machine is mainly composed of controller, filter, Venturi fertilizer absorber, sensor, level gauge, water pump, fertilizer pump, solenoid valve and other components. The working process of water and fertilizer with a certain EC value and $\mathrm{pH}$ value is as follows: After the agronomist sets the $\mathrm{EC}$ value and $\mathrm{pH}$ value of water and fertilizer to be deployed, the water and fertilizer machine starts to work. First, start the water pump and pump the irrigation water from the water source into the fertilizer tank through the filter. When the water level exceeds the low level meter, the fertilizer pump starts to work and pumps the water into the branch, and the water flows into the Venturi fertilizer absorber from the branch. When EC sensors and $\mathrm{PH}$ sensors to detect the current of water EC value and $\mathrm{PH}$ have not reached set value, the controller will be based on the algorithm of electromagnetic valve of the mother liquor tank, acid or alkali liquor pot of electromagnetic valve to control the on and off, when the solenoid valve opens, mother liquor, acid or alkaline solutions will depend on the negative pressure of venturi absorption of fat by suction pipe, into the mixed fertilizer tank and mix water, By controlling the opening time of solenoid valve of mother liquor tank, acid liquor tank and alkali liquor tank in each cycle of the controller, the $\mathrm{EC}$ value and $\mathrm{pH}$ value of water and fertilizer in the fertilizer mixing tank reach the set value, and then irrigate the soil[6].

The three mother liquid tanks of the water fertilizer machine are nutrient liquid, acid liquid and alkali liquid respectively. Nutrient solution is used to adjust the EC value of water and fertilizer in nutrient solution, and acid solution and alkali 
solution are used to adjust the $\mathrm{pH}$ value of water and fertilizer. The EC value collected by the sensor is compared with the required $\mathrm{EC}$ value of the crop, if the current ECIf the value is lower than the target EC value, open the solenoid valve to add nutrient solution. If the current $\mathrm{EC}$ value is higher than the target EC value, open the solenoid valve to add water. The control of $\mathrm{pH}$ value is realized in the same way.

The intelligent water and fertilizer integration device integrates the environmental monitoring system and the intelligent water and fertilizer integration system, which is composed of three parts. Wireless sensor network is composed of multiple sensor nodes of wireless network, wireless sensor network (WSN) is responsible for collecting information of crop growth environment (soil moisture, air temperature and humidity, light intensity), cucumber system device by all-in-one, water supply, water supply equipment, such as ratio of cucumber system is responsible for according to the instructions must be conductivity and ph value of sewage sludge, Then the soil is fertilized and irrigated. The sensor node and the water and fertilizer integrated machine jointly form a wireless sensor network, with the sensor as the terminal node and the water and fertilizer integrated machine as the coordination node.

The terminal node will pack the collected information and send it to the all-in-one water and fertilizer machine. The all-in-one water and fertilizer machine will collect the information collected by the sensor and send it to the remote monitoring system. The remote monitoring system can monitor the front-end environmental information and water and fertilizer information and control the operation of the front-end equipment. Sensor network: (1) is suitable for planting environment is the guarantee of a necessary condition for the healthy growth of crops, so wireless sensor network, this system adopts the wi-fi technology on crop growth environment of soil moisture, air temperature and humidity and light intensity for real-time monitoring, the planting environment monitoring field planting environment and control parameter is the user data basis of fertigation.(2) the integration system: water integration system consists of water supply system, water supply system and all-in-one water, its core is all-in-one water, sewage sludge machine as the control equipment of this system, responsible for providing power to the liquid fertilizer, water, acid and alkali raw materials such as mixture is suitable for the growth of the crops, water for crop irrigation fertilization.(3) Remote monitoring platform: Users can through the remote monitoring platform housebound monitoring of crop growth environment information, control the running status of information and systems, water at the same time users can set parameters automatically to control crop fertilizer irrigation, also can match with the manual control system of the solenoid valve fertilizer, fertilizer application, operation can also to query the history information.

\subsection{Test results}

The biggest difference from the previous integration of water and fertilizer is that the design is based on the growth characteristics of raspberry, which has the significance of popularization. It can be promoted to fruit tree plantations such as winter jujube, and the organic combination of artificial intelligence and modern agriculture is made. Mobile APP function, The APP designed and developed according to the demand of modern agricultural mode mainly includes the interface of weather forecast, communication, technical parameter setting interface of water and fertilizer integration, as well as the interface of historical data recording and curve display, which can remotely detect and control the equipment of water and fertilizer integration. Cloud platform, Both the user layer and the expert layer can remotely detect crop growth to achieve data sharing, and the experts can remotely query the historical management scheme to provide users with guidance on water and fertilizer, so as to realize the development of high-quality agricultural mode with intelligent technology.

\section{CONCLUSION}

Raspberry picking garden by using intelligent integration equipment, water can save a lot of manpower material resources, saving a lot of artificial cost, the calculation of $100 \mathrm{mu}$ book raspberry picking garden using smart cucumber in equipment picked two season costs about 1 million yuan a year, if the Bin Zhou city fruit and vegetable garden all use the equipment, save cost hundreds of millions of dollars a year. The General Office of the Ministry of Agriculture issued the Implementation Plan for Promoting the Integration of Water and Fertilizer (2016-2020) on November 27 , 2017, which clearly proposed to vigorously develop water-saving agriculture, implement the zero-growth action of chemical fertilizer usage, popularize farmland water-saving technologies such as the integration of water and fertilizer, and comprehensively improve farmland water production efficiency and fertilizer utilization rate. It is the only way to ensure national food security, develop modern water-saving agriculture, transform agricultural development mode and promote sustainable agricultural development. The Ministry of Water Resources issued the Guiding Opinions on Deepening the Reform of Farmland and Water Resources on March 4, 2018, which clearly proposed to promote the upgrading of farmland and water conservancy facilities, strengthen the combination of water-saving irrigation projects with agronomy, agricultural 
machinery, biology, management and other measures. Therefore, the integrated intelligent irrigation system of water and fertilizer based on the Internet of Things technology is a research subject supported by the national industrial policy. At the moment when China is implementing the rural revitalization strategy, the research on intelligent irrigation system of integrated water and fertilizer based on the Internet of Things is conducive to improving the intelligence of agricultural irrigation equipment, improving the efficiency of agricultural production and the quality and safety of agricultural products, and laying a solid foundation for the realization of agricultural modernization.

\section{REFERENCES}

[1] Yao Rui.Research and Development of Intelligent Fertilizer Distribution Control System Based on Internet of Things Architecture [D]. Shandong University,2018SUN L L. Study on integrated fertilization model of water and fertilizer in apple orchard[D]. Shandong Agricultural University,2018. (in Chinese with English abstract)

[2] Chen Zhuoji, Yu Raspberry Pi, Research and Design of Greenhouse Networking Monitoring System [D]. Xi 'an Technological University, 2018.
[3] Jiang Zaiyang, Wang Beibei, Li Mingfang, Liu Wenhui. Design of integrated field water and fertilizer system based on crop growth environment monitoring $[\mathrm{J}]$. Agricultural Engineering Technology, 2019, 39(27): 47-49.

[4] Li Kai, Yin Yilei, Hou Yong. Application status and development trend of water and fertilizer integration equipment for protected horticulture in China [J]. Agricultural Engineering Technology, 2018, 38(04): 16-21.

[5]ChangjianLi.,YunwuXiong.,Quanzhong Huang.,XuXu.,GuanhuaHuang..Impact of irrigation and fertilization regimes on greenhouse gas emissions from soil of mulching cultivated maize (Zea mays L.) field in the upper reaches of Yellow River, China[J].Journal of Cleaner Production, 2020, 259:1-15.

[6] P. Xu, J. Cao, et. al., Quantum chemical study on the adsorption of megazol drug on the pristine BC3 nanosheet, Supramolecular Chemistry, 33(2021)63-69.

[7] P. Xu, C. Geng, et. al., Application of Boron-doped Graphdiyne (BGDY) in Dehydrogenation of Benzyl Alcohol to Benzaldehyde, Basic \& Clinical Pharmacology \& Toxicology, 128SI3(2021)97-98. 